\title{
EVOLUTION OF THE NATURAL GROWTH AND THE ANALYSIS OF THE SEASONALITY OF LIVE BIRTHS AND DEATHS FROM ROMANIA AND BACAU COUNTY IN THE LAST FOUR YEARS
}

\author{
Eugenia Harja \\ "Vasile Alecsandri” University of Bacau \\ eugenia.harja@ub.ro \\ Oana-Ancuța Stângaciu \\ "Vasile Alecsandri” University of Bacau \\ anca_stangaciu@yahoo.com
}

\begin{abstract}
Since 1992, Romania's population declined every year naturally, the number of deaths being higher than live births. If in Bacau until 2002 we had to deal with natural growth of the population, even if increasingly less, starting that year it emerged more and more the process of decline of the population. In both cases, the phenomenon is more pronounced in rural areas than in urban areas due to more pronounced aging of the rural population. Both in the case of live births and deaths it is observed the seasonal oscillation by the months of the year. If in the case of births they are more numerous in the summer months and in decrease in the winter months, the situation is exactly the opposite in the case of deaths. Thus from here we have the natural decrease of the population, which increases in the winter months and starts to decline or become slightly positive in July-September.
\end{abstract}

\section{Keywords}

seasonality indices; live births; deaths; natural growth

\section{JEL Classification}

C10; J10; J11

\section{Introduction}

Knowing the evolution in time of the demographic phenomena and the factors that influence it underline its great importance in estimating the population and age structure. If we consider the population as a closed system, without taking into account the migration, its evolution depends on the two demographic phenomena: birth and death rates.

The evolution of the birth rate in a country is influenced by existing family policies and it depends on the intention of the couples in terms of the number of children they wish to have. In parallel, mortality depends on the age structure of the population, the state health system, and the general living conditions. In the last years, Romania has experienced a birth rate becoming smaller and a higher mortality. The latter was higher due to a poor health system, which could not cope with an aging population and insufficient livelihood means. The opposite evolutions of birth and death rates have led to the worsening decline of the population naturally, from $-0,9 \%$ in 2000 at national level and $+0,9 \%$, reaching at the end of the period $-2,6 \%$ nationally and $1,9 \%$ at county level. These negative evolutions, coupled with a negative migratory growth, led and still lead to a decrease in the population of our country, but also to an unbalanced age structure in favor of the elderly. 


\section{Evolution of the live births, deaths and growth rate}

The monthly evolution of the live births and deaths from the last years can be observed for Bacau county compared to Romania in figures 1 and 2.

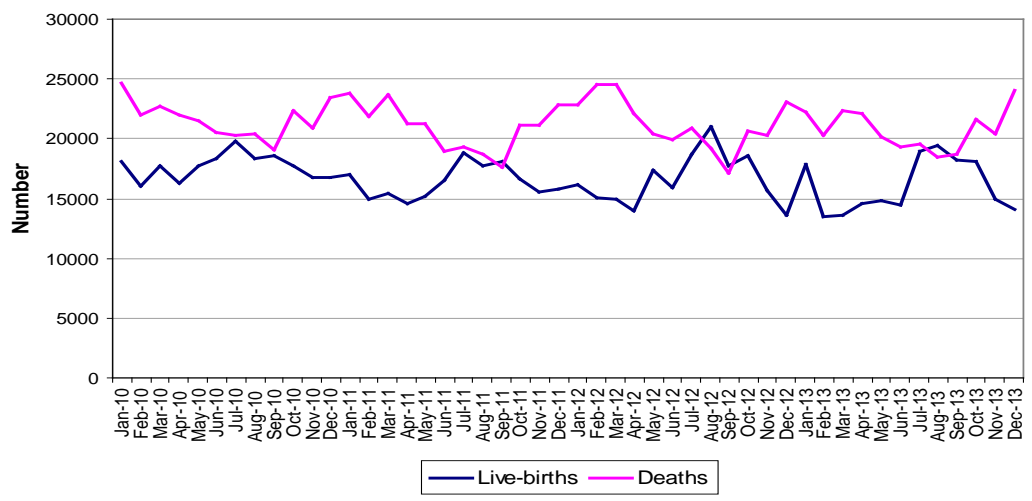

Figure 1 Evolution of the number of live births and deaths in Romania, for the months of the years 2010-2013

Source: I.N.S., Tempo online

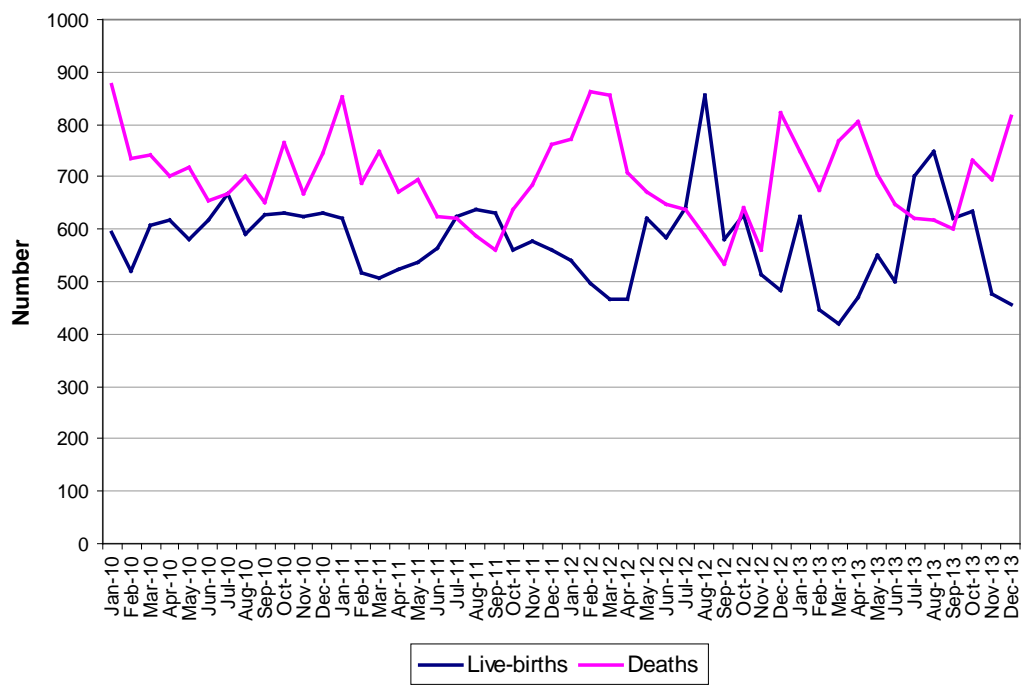

Figure 2 Evolution of the number of live births and deaths in Bacau county, for the months of the years 2010-2013

Source: I.N.S., Tempo online

It can be noticed that the evolution of the two phenomenon follow a somewhat similar evolution from year to year. Thus, the live births one is higher during summer months and lower as we approach the cold months. This phenomenon has been observed for many years in most of the countries with the same climate. One explanation could be that in the winter months couples retire from the field work, especially in rural areas, focusing more on life of the couple. On the other hand, families where family 
planning works, they want their children to start their life in the spring-summer months in order to grow and develop a little until the cold is coming.

In the case of Romania, the peaks of the births are July and August and the months of December and February are recorded with a minimum.

In Bacau county, peak months are from July to September, while the lows are especially February and March.

In the case of deaths, the evolution is opposite to the one of births. Thus, in the winter months due to unfavorable weather conditions, persons at risk of death (especially children and the elderly) get sick easier and have a higher probability of dying. For this reason we have more naturally decrease during the winter months.

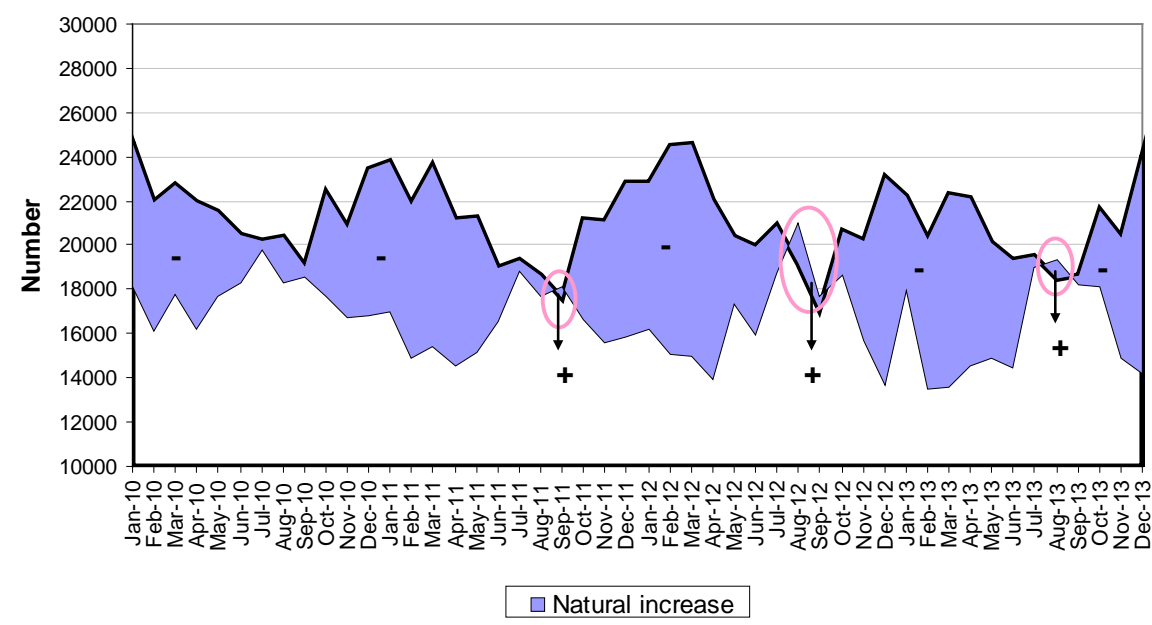

Figure 3 Evolution of the growth rate of the population from Romania during 2010-2013

Source: own calculations based on data from the Institute of Statistics from Bacau County

Both in the case of Romania and Bacau county, the maximum deaths were observed during the months of December and January, but as winter was extended in 2012, deaths peaks were observed also in February-March or even April. Following the evolution of the two demographic phenomena, the natural growth rate was negative for most of the year. From Figure 3 it can be noticed that the only months in which the country has had a slightly natural increase of the population was in the following months: September 2011 (+518 persons), in August 2012 (+1835 persons), September 2012 (+596 persons ) and August 2013 (+858 persons). The month with the highest natural decrease of the population in the country was December 2013 (-9885 persons). 


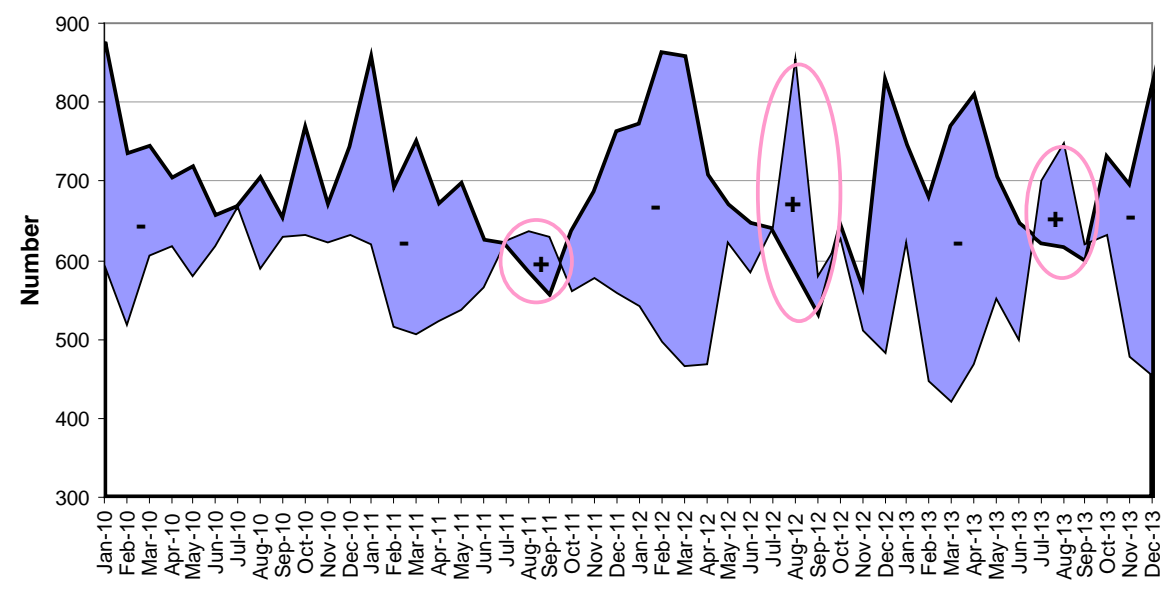

$\square$ Natural increase

\section{Figure 4 Evolution of the growth rate of the population from Bacau County during 2010-2013}

Source: own calculations based on data from the Institute of Statistics from Bacau County

In the case of Bacau County, there are outlined in the chart three periods with a higher natural growth of the population during July-September 2011-2013. The maximum negative figure was observed in March 2012, followed by February 2012 and December 2013.

Since both births and deaths manifest a clearly seasonal oscillation, we moved on to the statistical analysis of this phenomenon.

\section{Seasonality indices}

Seasonality indices measure the deviation of the phenomenon from the monthly yearly average. Because the repeating graphics of the two demographic phenomena is observed every 12 months, there were calculated mobile averages of 12 terms, and finally these were centered in the right of an initial term, by averaging the two terms. The influence of the trend component was eliminated by dividing the real terms with the centered mobile averages, and in the end, using the arithmetic mean method to calculate the monthly indices of pure seasonality.

The calculated indices of seasonality were presented comparatively in Figures 5 and 6. in Romania, the average number of births per month deviates from the monthly average annually with $+14,3 \%$ in July, $+13,9 \%$ in August, $+9,2 \%$ in September, $+7 \%$ in October, and in January with $+4,5 \%$. Practically January contradicts the theory mentioned before. The months recording minimum figures are February, March and April, when the average monthly number of live births was with $-12 \%$ lower than the annual average.

In Bacau county, every year, we have with $+20,4 \%$ born in August compared to the annual average, with $+11,4 \%$ in July, $+6,8 \%$ in September, $+6,4 \%$ in October, $+5,3 \%$ in January and with $+0,5 \%$ in November. The seasonality indices calculated indicate an average number of live births each year less than the annual average with $-18,5 \%$ in March, $-14,6 \%$ in April and -4,3\% in February.

Regarding the seasonality indices calculated for deaths, in Romania, these indicate an average number of deaths above the annual average during the following months: in 
March with $+11,8 \%$, in December $+9,4 \%$, in January $+8,9 \%$, February $+5,4 \%$, in April $+3,9 \%$ and October with $+1 \%$.
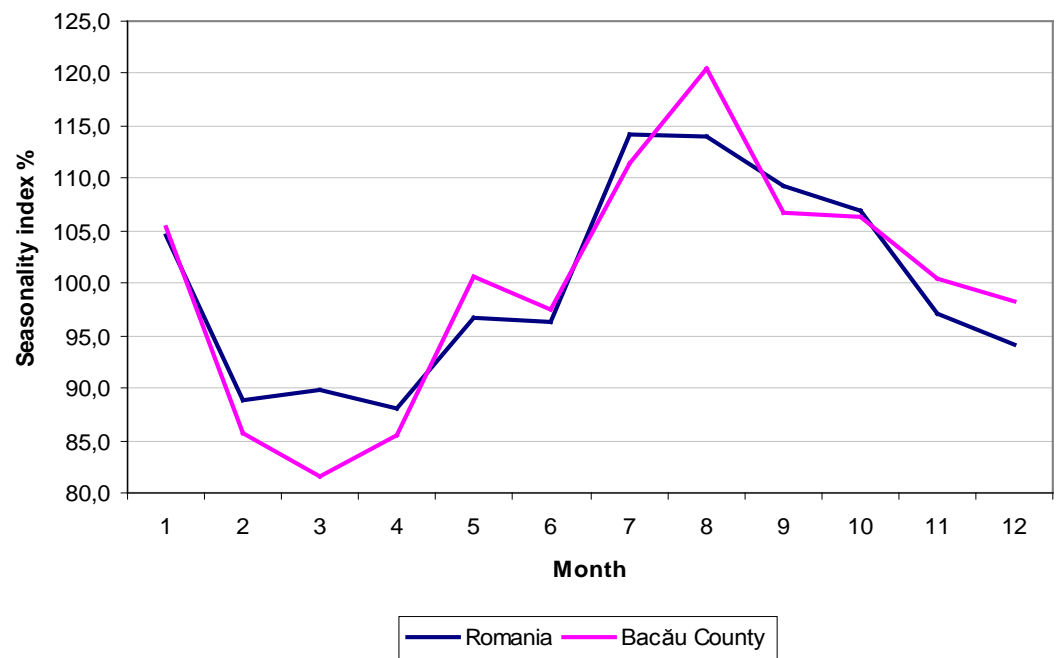

Figure 5 Monthly seasonality indices calculated by the mobile average method for live births during 2010-2013

Source: own calculations based on data from the Institute of Statistics from Bacau County

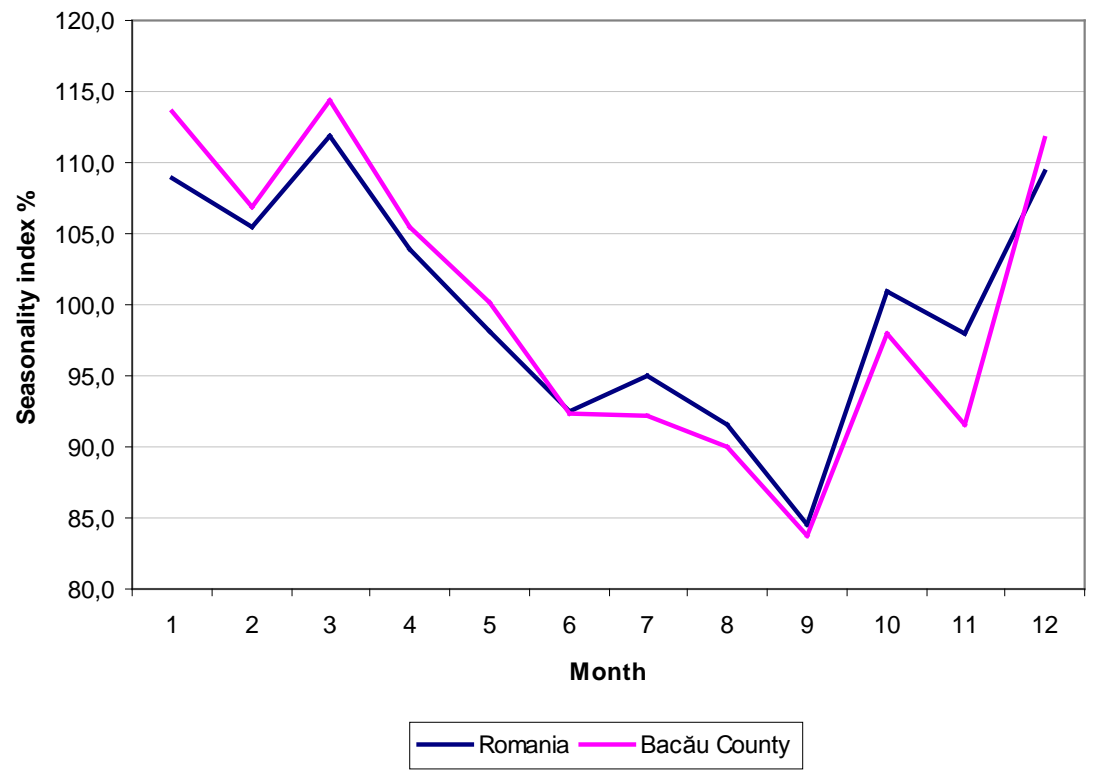

Figure 6 Monthly seasonality indices calculated by the mobile average method for deaths during 2010-2013

Source: own calculations based on data from the Institute of Statistics from Bacau County

In contrast, an average number of deaths under the annual average were observed primarily in the months of September $-15,4 \%,-8,4 \%$ in August, June -7,6\% and July $5,1 \%$. 
In Bacau County, the seasonality indices calculated for deaths indicate a $+11,8 \%$ in March, followed by $+9,4 \%$ in December, $+8,9 \%$ in January, $+5,4 \%$ in February, $+3,9 \%$ in April and $+1 \%$ in October. The lowest seasonality indices were calculated for the months of September (-16,2\%), August (-10\%), July $(-7,8 \%)$ and June $(-7,6 \%)$.

Comparing the evolution of the seasonality indices from the two graphs, it can be observed that there are significant differences between the indices calculated for the national level and those calculated for Bacau County.

\section{Conclusions}

After the 90's, the number of live births has been declining continuously, without even assuring the simple reproduction of the population. Instability of a steady income, women's desire to achieve economic independence from the partner, the migration of young people abroad, are just some of the factors that led to the delay of the moment of bringing a child to life and the decision of couples to have a number small children. On the other hand, the increasing of life duration of the population, on the grounds of an aging population left within the country and poor health system, turned into a slight increase in the number of deaths. The correlated evolution of the two demographic phenomena has led to a continuous negative increase, more pronounced in the country compared to Bacau County. It turned out from the monthly evolutions of the past four years that both demographic phenomena have a seasonal component with higher number of births especially in the summer months and a higher number of deaths in the cold months.

These evolutions should be taken into account in estimating the population monthly trends when they are produced, if not taken into account economic and demographic policy measures. These measures should stimulate the birth rate on the one hand; on the other hand lead to the improvement of health care and greater attention to prevention and health.

If governments that succeed do not take actions in this direction, young, active and in power work force, within the Romanian state's expense, will continue to go abroad, and the country will remain with the elderly, sick and helpless, without a real support. This is unfortunately the trend from the last few years in Romania!

\section{References}

Barthelemy, P., Granier, B., Robert, M. (2009), Demografie şi societate, Institutul European.

Harja, E. (2009), Statistică şi econometrie, Bacău, Ed. AlmaMater.

Institutul National de Statistica (2014), TEMPO Online, available at http://www.insse.ro/.

Rotariu, T. (2003), Demografie şi sociologia populaţiei, Ed.Polirom, Iaşi. 